\title{
A paired-associates learning task involving two sensory modalities
}

HAROLD A. RIES

UNIVERSITY OF KENTUCKY 1

Thirty Ss served in a paired-associates learning task using three different sets of color-tone pairs. The data indicated that a "synesthetic" pairing of the colors and tones, based on correlated physical characteristics of the sense modalities, markedly influenced the rate of acquisition of these pairs. This group learned the pairs with significantly less errors and trials than did the other groups in which the pairs were randomly determined even though the "synesthetic" pairings were not preferred in a pre-learning task.

The phenomenon in which a stimulus involving one sensory modality elicits a response belonging to another sensory modality has been defined as synesthesia. Although observations of this phenomenon have been recorded in the literature for over a century, most reports deal only with an individual case which received attention because of its "uniqueness." Experimental research in this area has tended to be characterized by one technique. An auditory stimulus is presented and the Ss are instructed to name a visual phenomenon, such as a color, adjective, or geometric form, which seems to describe the stimulus. There are two studies, however, which did not follow this general procedure. Kelly (1934) and Howells (1944) attempted to induce visual hallucinations to auditory stimuli by conditioning techniques. While they arrived at opposite conclusions concerning the production of synesthesia via this method, a review of their data indicates that the Ss in both studies learned the auditory-visual associations relatively rapidly. However, the level of difficulty for the acquisition of these auditory-visual pairings cannot be evaluated precisely because neither study used control groups. This problem assumes importance because most investigators state or assume that physical correlations exist between the senses. Unless it can be demonstrated that some auditory-visual pairings can be learned more efficiently than others, the concept of synesthesia would seem to be superfluous.

The purpose of the present investigation is to test the hypothesis that certain pairings of colors and tones, based on correlations of the physical properties of these modalities, will be learned more efficiently than will pairings which are randomly determined.

Method

Subjects. Thirty students from the University of Kentucky volunteered to serve as Ss. All were naive regarding the method and purpose of the present study. Differences between groups on age, classification and sex were negligible. Each $S$ was randomly assigned to one of three groups of $10 \mathrm{Ss}$ each.
Group S: The "synesthesia" group learned the colortone pairings correlated in terms of comparable physical continua. The colors were ranked according to their relative wave length and the tones according to their relative cps, and these continua were directly correlated. The color-tone pairings were: red, $8000 \mathrm{cps}$; orange, 6000 cps; yellow, $2000 \mathrm{cps}$; green, $500 \mathrm{cps}$; and blue, $125 \mathrm{cps}$.

Group R: The "random" group learned a random pairing of the colors and tones, although these pairings remained constant throughout the task. The color-tone pairings were: orange, $8000 \mathrm{cps}$; blue, $6000 \mathrm{cps}$; red, $2000 \mathrm{cps}$; yellow, $500 \mathrm{cps}$; and green, $125 \mathrm{cps}$.

Group C: The "chance" group learned a random pairing of the colors and tones which changed on each succeeding trial, that is, the pairs were randomly predetermined for every trial. This group was included to provide a "chance baseline" against which the learning efficiency of the other groups could be evaluated.

Apparatus. The apparatus consisted of (1) an Advance Clinical Audiometer, Maico Model MA-1, and (2) a Constant Illumination Ralph Gerbrands tachistoscope with an illuminated field of $20 \mathrm{~cm} \times 20 \mathrm{~cm}$. The audiometer was preset at $60 \mathrm{~dB}$ above audiometer zero and the auditory intensity level remained constant for all tone presentations. The pure tone stimuli were presented binaurally to the $\mathrm{S}$ through earphones held by Maico headset. Pure Tempera pigment was applied directly, in 2 in. $x 2$ in. squares, on $20 \mathrm{~cm} \times 20 \mathrm{~cm}$ white cards which were presented in the tachistoscope.

Procedure. Following a screening procedure to eliminate tone-deaf or color-blind Ss, the tones used in the study were presented from the highest to the lowest tone and the Ss were instructed to report the first color which came to mind when they heard the tone. Next, the tones were presented in a predetermined random order which was identical for all groups for any given trial but whose order differed for each succeeding trial. Ss were instructed to "predict" the color which would be presented in the tachistoscope. All tones were presented for 3-sec. intervals and, when the Smade his choice of colors, the plate was made visible in the tachistoscope for a period of 3 sec. Ss were not aware of the specific colors used until aftertrial 1. Each trial consisted of one presentation of each of the five tones and no tone was presented more than once in any given trial. At the end of each trial the $S$ was informed of the number of correct predictions he had made and when he correctly predicted all five colors in any given trial, this portion of the experiment ended. At this time the 
tones were again presented from the highest to the lowest and the Ss were again instructed to report the first color which came to mind when they heard the tone. They were told that it did not matter if their choices agreed with the learned pairings or their previous pairings. Ss then were interviewed concerning methods used in predicting the color-tone pairings.

\section{Results}

The pre-learning task color-tone pairings were determined by ranking the tones from highest to lowest in an ascending order and determining the mean rankings of each color. Despite the expectation that these preferences would be highly correlated with Group S's learned pairings, only a small, non-significant correlation was found $(r=.12, n . s$.$) . The colors were ranked$ in descending order as: yellow, green, red, blue and orange. This arrangement was essentially a reverse ranking of the learned pairings for Group $\mathrm{R}$ and the pretask preferences for the Ss in Group $R$ were highly negatively correlated with their learned pairings $(r=-.42, p<.01)$ 。

The learning data were analyzed using the number of errors committed by each group and the number of trials required by each group to reach the criterion of one errorless trial. Sixteen trials were analyzed, allowing for a possible 80 errors per $\mathrm{S}$, at which point all members of Groups $\mathrm{S}$ and $\mathrm{R}$ had reached the experimental criterion. One $\mathrm{S}$ in Group $\mathrm{C}$ reached this criterion on trial 15.

The mean number of errors committed during these 16 trials were: Group S, 8.0; Group R, 19.8; and Group C, 52.8. Because Group C showed no evidence of learning during the task, the analysis of variance used to investigate error differences included only data from Groups $S$ and $R$. This analysis revealed significant error differences between these two conditions on Groups $(F=8.80, p<.01)$, Trials $(\mathbf{F}=28.31, \mathrm{p}<.001)$ and on the Groups by Trials interaction $(F=5.31, p<.001)$. These results indicate that Group S committed significantly less total errors than did Group R.

The mean number of trials required to reach the criterion for Group $\mathrm{S}$ was 3.2 and for Group $\mathrm{R}$ was 8.1. The analysis of variance analyzing the number of trials necessary for Groups Sand $\mathrm{R}$ to reach the criterion also revealed significant differences between Groups $S$ and $\mathbf{R}(\mathbf{F}=11.58, \mathrm{p}<.01)$. These results indicate that Group $S$ required significantly less trials to learn the colortone pairings than did Group R. The post-task colortone associations reveal high positive correlations between the group preferences and the learned pairings. The correlation for Group S is .66, $\mathrm{p}<.01$, and for Group $\mathbf{R}$ is $.64, \mathrm{p}<.01$. These results indicate that the learning portion of the present task, which presented "correct" associations markedly influenced the post-task associations for Groups $\mathrm{S}$ and $\mathrm{R}$. Group $\mathrm{C}$, where the correct answers were altered for each trial, maintained their pre-task preferences with only minor changes $(\mathrm{r}=.55, \mathrm{p}<.01)$.

\section{Discussion}

The results of the present study indicate that the pairing of colors and tones according to correlated physical characteristics results in a more efficient learning of these pairs as defined by the number of trials required to learn the task and by the number of errors committed during this iearning process. It may be noted that significant differences in the errors of Groups $S$ and $\mathbf{R}$ were found by trial 2 .

It had been expected that previous learning experiences, such as familiarity with color wheels, would have influenced the acquisition rates in the present task. In the post-experimental interview, however, Ss in Group $S$ seemed oblivious to this possibility and their reports were of the nature that "the pairings just seemed right." Ss in Group $R$ indicated that while the associations seemed "wrong," they resorted to memorization. None of these Ss seemed to be aware that their "correct" ranking was almost a reversal of their pre-task preferences. Ss in Group C characteristically used complex strategies, such as assuming that the task involved periodically shifting associations in which they were expected to predict the future shifts in order to make the correct predictions. Thus, the conscious use of prior learning or strategies was not used by Groups $S$ and $R$ because the task was too simple and they emerged only when the task appeared highly complex, as it was interpreted by Group $C$.

Contrary to expectations, the pre-task color-tone associations did not reflect the physical correlations that might have been expected on the basis of the relatively rapid learning of the "synesthesia" pairings. Not a single $S$ used the "synesthesia" pairing of the colors and tones during the pre-task associations, nor were the color-tone associations of any $\mathrm{S}$ identical with those of any other S. However, most Ss did pair yellow, red and green with high tones and orange and blue with low tones. Thus, despite the emphasis of former investigations (Daub, 1937; Hollingsworth \& Weicher, 1939; Langfeld, 1929), it is not the ability to associate colors with tones which is unique, for all Ss participated in this task with no difficulty. Rather, it is the tendency for most $\mathrm{Ss}$ to associate groups of colors with a relative high or low tone position which enhances the learning of pairings based on these associations.

\section{References}

Daub, F. Ein Fall von 'synoptischem' absolutem. Gehor, Sangew Psychol., 1937, 52, 243-250.

Hollingsworth, H., \& Weischer, V. Persistent alphabetical synes thesia, Amer. J. Psychol., 1939, 48, 264-268.

Howells, T. The experimental development of color-tone synesthesia. J. exp. Psychol., 1944, 34, 87-103.

Kelley, E. An experimental attempt to produce artificial chromaesthesia by the technique of the conditioned response. $J$. exp. Psychol., 1934, 17, 315-341.

Langfeld, H. Synesthesia. Psychol. Bull., 1929, 26, 582-585. Note

1. Now at Stockton State Hospital, California. 